Tropical Journal of Applied Natural Sciences
Trop. J. Appl. Nat. Sci., 2(1): 21-24 (2017)
ISSN: 2449-2043
https://doi.org/10.25240/TJANS.2017.2.1.05

\title{
Fasciola hepatica Infestation in Slaughtered Cow Liver in Eke Uli Market Abattoir, Ihiala Local Government Area of Anambra State, Nigeria
}

\author{
*Anyaegbunam, Lucy C. and Ajana Uchenna \\ Department of Biological Sciences, Chukwuemeka Odumegwu Ojukwu University, Nigeria \\ *Corresponding author's email: lcanyaegbunam@yahoo.com.
}

\begin{abstract}
The evaluation of Fasciola hepatica infestation in sampled cows slaughtered in Eke Uli abattoir was carried out from July to September 2014. A total of 128 livers of slaughtered cows were examined by making lengthwise incision on the ventral side with the bile duct and gall bladder cut open. According to the period of examination, July recorded prevalence of $12.5 \%$ while August and September had $11.7 \%$ and 40.0\% respectively. Among the 128 livers examined, 21(16.4\%) were infected. The diseased livers in terms of parasite load stood at $13(61.9 \%)$ light parasite burden, $6(28.6 \%)$ medium load and $2(9.6 \%)$ heavy load. This situation calls for veterinary workers attention in the abattoir, for heavily infested livers were sold for human consumption according to the dealers. This will help to forestall human infestation by the parasite.
\end{abstract}

\section{Original Research Article}

Received: $30^{\text {th }}$ Aug., 2017.

Accepted: $21^{\text {st }}$ Oct., 2017.

Published: $23^{\text {rd }}$ Oct., 2017.

Keywords:

Abattoir; Cow; Eke;

Fasciola hepatica;

Infestation; Liver.

\section{INTRODUCTION}

$F$ asciola hepatica, a common liver fluke is a diagnostic Trematode and belongs to the family Fasciolidae. It is an important liver parasite of ruminants. It inhabits the bile duct and gall bladder where it causes severe damage which may lead to death of infested animal (Anosike et al., 2005).

The disease effect Fasciolasis, constitute both economic and public health constraints to profitable ruminant production in the Tropics. Fasciolasis has been incremented as the cause of morbidity and mortality in the production of ruminants (Onwuliri et al., 1993; Okoli et al, 2000). The nutritional and health value of infested animals deteriorate leading to poor carcass quality and loss.

Adult flukes are found in the bile ducts of liver, but occasionally small adults are found encapsulated in cancerous nodular lesions in the lungs. Acute and sub-acute forms of fasciolasis develops $2-3$ weeks after massive infections and signs include anorexia, abdominal pains, yellowish and pale conjunctiva, weight loss and sudden death. Migratory juvenile flukes cause haemorrhagic tracts in liver parenchyma, with associated peritonitis. Heavy infestation may cause death in the stage of acute hepatitis (acute fascioliasis) and Black disease caused by Clostridium novyi intoxication (Love and Hutchinso, 2003).
Human cases have been reported in the Tropics in parts of Africa and Hawaii. Human infection is by eating raw watercress and water plants as snacks or salad which are contaminated with immature forms of the parasite. Symptoms include gastrointestinal problems such as nausea, vomiting, abdominal pains, fever and breathing difficulty may occur. This work however, will involve post mortem examination of cow livers in a local abattoir in Uli which has no idea of Veterinary inspection. In this area it was observed that even the heavily infested livers were sold for human consumption.

\section{MATERIALS AND METHODS}

The study was carried out in Eke market abattoir in Uli, a town in Ihiala Local Government Area of Anambra State from July to September 2014. Uli is a growing community and is located between $6^{0} 47^{\prime}$ to $6^{0} 57^{\prime} \mathrm{E}$ and $5^{\circ} 58^{\prime}$ to $5^{0} 40^{\prime}$ $\mathrm{N}$.The inhabitants are mostly petty traders, farmers and few civil servants.

\section{Collection of liver specimens}

The visit to the abattoir for the study was made possible with the consent of the chairman of butchers in the community and the assistance of his workers. The slaughter house was visited four times every week throught the period of the study. The work involved post-mortem examination on the cow liver. 
One hundred and twenty eight (128) cow livers were examined for the presence of Fasciola hepatica. The sampled cow livers were opened by length wise incisions of ventral side which cut open the bile duct.

With the use of forceps, recovered flukes were picked into transparent universal bottles. These were separated according to the period of collections.

\section{Identification of Fluke}

Fluke's identification was based on their morphological peculiarities such as leaf shape and flattened body which is pointed posterioly and wide anteriorly. The intensity of infection was based on the number of flukes recovered from each infested liver. These were classified into light infection $(1-10)$, medium $(11-30)$ and heavy infestation (31 and above).

\section{RESULTS}

Among the 128 livers examined in this study, the following results were obtained (Table $1 \& 2$; Plate $1 \& 2$ ).

\section{DISCUSSION}

The infection rate of $F$. hepatica in the cow livers examined was $16.41 \%$ which can be said to be moderate though no similar study was known to have been carried out in the area. A comparison of this was in Nsukka Urban abattoir (Ikem and Obioha, 1973) in which they came up with 39\% rate. The most current work was recorded by Ngwu et al (2004) with $10.0 \%$ prevalence. However, Ekwunife and Eneanya (2004) recorded $10.51 \%$ prevalence in Onitsha Urban abattoir. The overall prevalence of infection in the present study could be attributed to the period of the study, which was highest in September $(6.25 \%)$, the peak of rainy season. This confirms the work of Egbe-nwiyi and Ohuadrai (1996) in Borno State, with $41.3 \%$ in the rainy period and $32.7 \%$ in post rainy season. The high prevalence of $F$. hepatica in rainy season can be as a result of the abundance of snail intermediate host at this period of the year. In all these, Fasciola hepatica infection has remained a major intestinal and liver condemnation in cow. The situation in the study area calls for the attention of both veterinary workers and public health planners to create awareness to meat dealers and consumers on the consequences of Fascioliasis in both ruminants and man.

This study has clearly demonstrated the presence of Fasciola hepatica in cows slaughtered at Eke Uli market abattoir. Although the rate of infection was moderately low, the implications should not be overlooked. The grazing of cow should be restricted to less snail infected areas and their free movement could only be allowed during the dry period of the year.

Table 1: The prevalence of infestation of the cow livers examined within the specified period

\begin{tabular}{llll}
\hline Time & Number examined & Number infected & \% infection \\
\hline July & 48 & 6 & 4.69 \\
August & 60 & 7 & 5.47 \\
September & 20 & 8 & 6.25 \\
Total & $\mathbf{1 2 8}$ & $\mathbf{2 1}$ & $\mathbf{1 6 . 4 1}$ \\
\hline
\end{tabular}

September recorded the highest infection rate of $6.25 \%$ while the least was in July $(4.69 \%)$ and the overall rate of infection was $16.41 \%$.

Table 2: The intensity of infestation among the infected liver examined.

\begin{tabular}{lllll}
\hline Time & No of infected liver & $\begin{array}{l}\text { Light Infection } \\
(\mathbf{1}-\mathbf{1 0})\end{array}$ & $\begin{array}{l}\text { Infection intensity } \\
\text { Medium of Infection } \\
(\mathbf{1 1}-\mathbf{3 0})\end{array}$ & $\begin{array}{l}\text { Heavy infection } \\
\text { (30 and above) }\end{array}$ \\
\hline July & 6 & 4 & 2 & 0 \\
August & 7 & 5 & 2 & 0 \\
September & 8 & 4 & 2 & 2 \\
Total & $\mathbf{2 1}$ & $\mathbf{1 3 ( 6 1 . 9 \% )}$ & $\mathbf{6}(\mathbf{2 8 . 6 \% )}$ & $\mathbf{2 ( 9 . 6 \% )}$ \\
\hline
\end{tabular}

Among the 21 infected livers, 13 had light infection $(1-10)$ and 2 heavy infections ( 31 and above) as shown in the plates I and II.

\section{REFERENCES}

Anosike, J.C., Opara, M.N., Okoli, G.C and Okoli, I.C. 2005). Prevalence of parasitic helminthes among ruminants in Etiti area of Imo State, Nigeria. Animal Production Research Advances, 1(1): 13 -19.

Egbe-nwiyi, J.N and Ohuadrai, S.U.R. (1996). Observation on prevalence, haematological changes in cattle, sheep and goats naturally infected with Fasciola spp in Acid zone of Borno State, Nigeria, Pakistan Veterinary Journal.

Ekwunife, C.A and Eneanya, C.I (2004). The prevalence of liver helminthh parasites of ruminants in Anambra State Nigeria. Bulletin of Animal Health and Production in Africa, (44): $151-154$.

Ikeme, M.M and Obioha, F. (1973).Fasciola species infestation in trade cattle in Eastern Nigeria. Bulletin of Epizootic Diseases in Africa, 21(21): 259 -264. 
Love, S.C.J and Hutchinso, G.W (2003). Pathology and diagnosis of internal parasites in ruminants. University of Sidney gross patholofy of ruminants.Proceedings, post graduate foundation in veterinary science chapter $16 \mathrm{pg} 309-338$.

Ngwu, G.I., Ohaegbula, A.B.O and Okafor, F.C. (2004). Prevalence of Fasciola gigantica, cysticercus bovis hepatica and other disease conditions of cattle slaughtered in Nsukka Urban abattoir. Animal Research International, 1(1): 7 -11.
Okoli, I.C., Agoh, G. C., Idemili, G.C and Umesiobi, O.O. (2000) Bovine and Caprin Fascioliasis in Enugu State, Nigeria. Retrospective analysis of abattoir records (1993 - 1997) and six months prevalence study. Bulletin of Animal health and Production in Africa, (43): 7 - 11

Onwuliri, C.O.E., Anosike, J.C., Nkem,C.N and Payne, V.K (1993).. The ecology of animal parasitic nematodes in endemic area of Jos, Nigeria. Applied Parasitology, (34): $131-137$.

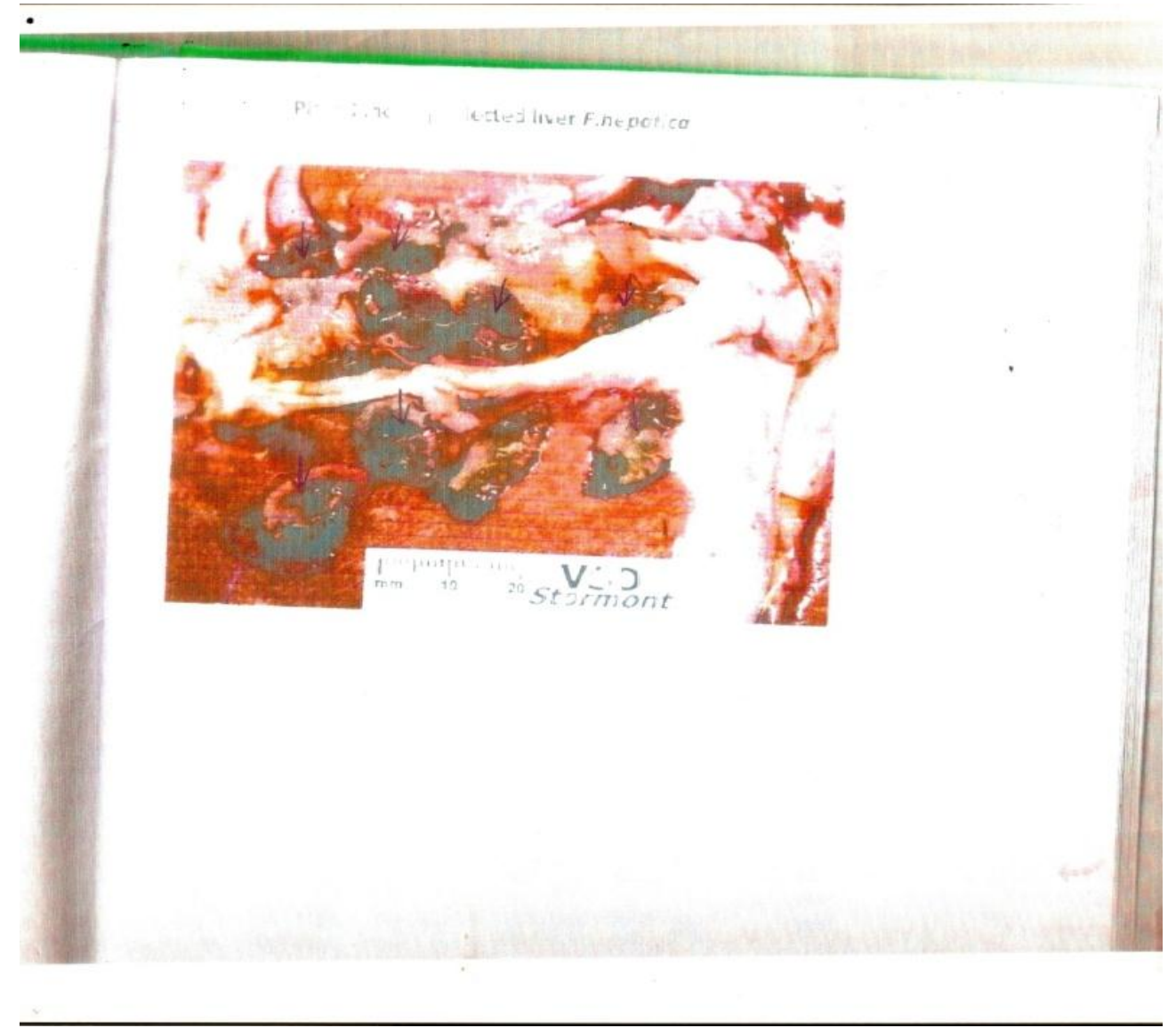

Plate 1: Heavily infested liver by Fasciola hepatica indicated by arrows. 


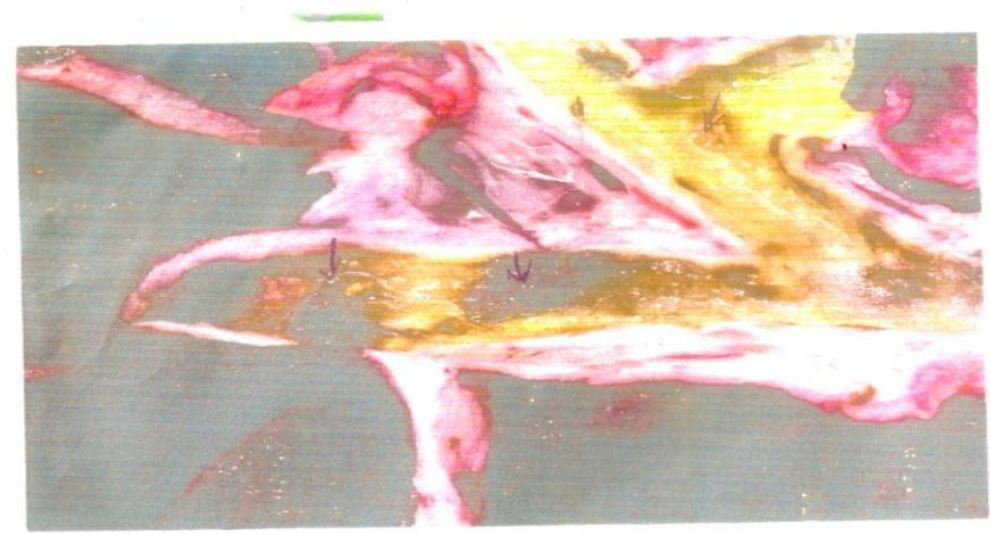

Plate 2: Medium/light infestation of liver by Fasciola hepatica.

\section{How to cite this article}

Anyaegbunam, L.C. and Ajana, U. (2017. Fasciola hepatica Infestation in Slaughtered Cow Liver in Eke Uli Market Abattoir, Ihiala Local Government Area of Anambra State, Nigeria. Tropical Journal of Applied Natural Sciences, 2(1): 21-24. Doi: https://doi.org/10.25240/TJANS.2017.2.1.05.

Licensed under a Creative Commons Attribution 4.0 International License 